\title{
Antegrade Percutaneous Versus Retrograde Ureteroscopic Lithotripsy in Upper Ureteric Cases
}

\author{
A. Nischal Prasad ${ }^{\circledR 1}$, PVGS Prasad ${ }^{\circledR 2}$ \\ ${ }^{1}$ Associate Professor, Department of Urology, Sapthagiri Institute of Medical Sciences and Research Center, Bangalore, Karnataka, India, ${ }^{2}$ Assistant Professor, \\ Department of Urology, Sapthagiri Institute of Medical Sciences and Research Center, Bangalore, Karnataka, India.
}

\section{Abstract}

Background: The technical advancements in urology have profoundly changed the management of upper ureteric calculus. The present study compared antegrade percutaneous versus retrograde ureteroscopic lithotripsy in upper ureteric cases. Subjects and Methods: The present study was conducted at NRI Medical College \& Hospital, Chinakakani, Mangalagiri Mandal, Andhra Pradesh from May 2013 to April 2014 on 60 patients with upper ureteric stones of both genders. Patients were divided into 2 groups. Group I patients were treated with antegrade percutaneous and group II with retrograde ureterolithotripsy. Outcome in both groups was recorded and compared. Results: The mean anesthetic time in group I was 82.4 minutes and in group II was 73.1 minutes, operative time was 45.2 minutes in group I and 58.4 minutes in group II, post- operative stay in group I was 2.6 days and in group II was 1.7 days, stone clearance was seen in 26 patients in group I and 22 in group II. Mean stone size in group I was $1.89 \mathrm{~cm}$ and in group II was $1.49 \mathrm{~cm}$. Follow ups days were 71.2 in group I and 83.4 in group II. Clavien-Dindo categorization grade 0 was seen in 16 in group I and 13 in group II, grade 1 in 10 in group I and 12 in group II and grade 2 in 4 in group I and 5 in group II. The difference was significant $(\mathrm{P}<0.05)$. There were 4 and 5 patients in group I and group II with post- operative complications $(\mathrm{P}<$ 0.05). Conclusion: Authors found that antegrade percutaneous has better stone clearance rates as compared to retrograde ureterolithotripsy for an upper ureteric calculus.

Keywords: Antegrade percutaneous, Clavien-Dindo, retrograde ureterolithotripsy

Corresponding Author: PVGS Prasad, Assistant Professor, Department of Urology, Sapthagiri Institute of Medical Sciences and Research Center, Bangalore, Karnataka, India.

E-mail: prasadmbbs2k@gmail.com

Received: 19 January 2020

Revised: 22 February 2020

Accepted: 12 March 2020

Published: 26 May 2020

\section{Introduction}

Large proximal ureteral stones can lead to urinary obstruction, which may be followed with renal function injury and life-threatening sepsis. ${ }^{[1]}$ Timely intervention to remove the stones completely is of great importance while the most appropriate treatment remains controversial. According to the latest American Urological Association (AUA) Guideline on surgical management of stones, extracorporeal shock wave lithotripsy (SWL) and ureteroscopic lithotripsy (URSL) have been proposed as the first-line treatments for proximal ureteral stone. ${ }^{[2]}$

The technical advancements in urology have profoundly changed the management of upper ureteric calculus. Before the introduction of shock wave lithotripsy (SWL) in 1980, open ureterolithotomy or basket extraction of stones under fluoroscopic guidance was the mainstay of treatment. However, currently, the blind basket extraction technique is obsolete, and open ureterolithotomy has been replaced by laparoscopic ureterolithotomy which is limited to a few indications such as a large, impacted calculus not amenable to SWL or endoscopic procedures. ${ }^{[3]}$

Current treatment of large proximal ureteral stones poses a therapeutic challenge and the best treatment modality still remains controversial. Although extracorporeal shock wave lithotripsy (SWL) represents a valuable option, retrograde ureteroscopic lithotripsy (URSL) and antegrade PCNL are both recommended as first-line treatment option according to most recent guidelines. ${ }^{[4]}$ However, there is no clear consensus in the literature regarding the optimal option. Large stone burden, concomitant impaction, and stone location in the proximal ureter are all factors that may decrease postoperative stone-free rate of retrograde approach and may lead to stone retropulsion into the kidney. On the other hand, antegrade technique is considered more invasive. ${ }^{[5]}$ The present study compared antegrade percutaneous versus 
retrograde ureteroscopic lithotripsy in upper ureteric cases.

\section{Subjects and Methods}

The present study was conducted in NRI Medical College \& Hospital, Chinakakani, Mangalagiri Mandal, Andhra Pradesh from April 2007 to March 2008 on 60 patients with upper ureteric stones of both genders. All were informed regarding the study and written consent was obtained. Ethical clearance was obtained prior to the study from ethical committee.

Data such as name, age etc. was recorded. A thorough clinical examination was done in all patients. Intravenous urography or computed tomography (CT) urography was performed in all the patients with normal renal function. Patients were divided into 2 groups. Group I patients were treated with antegrade percutaneous technique and group II with retrograde ureterolithotripsy. Outcome in both groups was recorded and compared. Results thus obtained were subjected to statistical analysis. $P$ value less than 0.05 was considered significant.

\section{Results}

\begin{tabular}{|lll|}
\hline \multicolumn{2}{|l|}{ Table 1: Distribution of patients } & \\
\hline Groups & Group I & Group II \\
Technique & $\begin{array}{l}\text { Antegrade } \\
\text { percutaneous }\end{array}$ & $\begin{array}{l}\text { Retrograde } \\
\text { ureterolithotripsy }\end{array}$ \\
& 30 & 30 \\
\hline
\end{tabular}

[Table 1] shows that group I patients were treated with antegrade percutaneous and group II with retrograde ureterolithotripsy. Each group had 30 patients.

[Table 2, Figure 1] shows that mean anesthetic time in group I was 82.4 minutes and in group II was 73.1 minutes, operative time was 45.2 minutes in group I and 58.4 minutes in group II, post- operative stay in group I was 2.6 days and in group II was 1.7 days, stone clearance was seen in 26 patients in group I and 22 in group II. Mean stone size in group I was $1.89 \mathrm{~cm}$ and in group II was $1.49 \mathrm{~cm}$. Follow ups days were 71.2 in group I and 83.4 in group II. Clavien-Dindo categorization grade 0 was seen in 16 in group I and 13 in group II, grade 1 in 10 in group I and 12 in group II and grade 2 in 4 in group I and 5 in group II. The difference was significant $(\mathrm{P}<0.05)$.

[Table 3] shows that there were 4 and 5 patients in group I and group II with post- operative complications $(\mathrm{P}<0.05)$.

\section{Discussion}

Choosing the optimal treatment modality for large proximal ureteral stones is challenging and it depends on several param-

\begin{tabular}{|c|c|c|c|}
\hline Parameters & Group I & Group II & P value \\
\hline $\begin{array}{l}\text { Anesthetic } \\
\text { time (mins) }\end{array}$ & 82.4 & 73.1 & 0.02 \\
\hline $\begin{array}{l}\text { Operative } \\
\text { time (mins) }\end{array}$ & 45.2 & 58.4 & 0.01 \\
\hline $\begin{array}{l}\text { Post- } \\
\text { operative } \\
\text { stay }\end{array}$ & 2.6 & 1.7 & 0.02 \\
\hline $\begin{array}{l}\text { Stone clear- } \\
\text { ance }\end{array}$ & 26 & 22 & 0.01 \\
\hline $\begin{array}{l}\text { Stone size } \\
(\mathrm{cm})\end{array}$ & 1.89 & 1.49 & 0.16 \\
\hline Follow up & 71.2 & 83.4 & 0.91 \\
\hline $\begin{array}{l}\text { Clavien- } \\
\text { Dindo } \\
\text { categoriza- } \\
\text { tion }\end{array}$ & - & - & - \\
\hline Grade 0 & 16 & 13 & 0.74 \\
\hline Grade 1 & 10 & 12 & \\
\hline Grade 2 & 4 & 5 & \\
\hline
\end{tabular}

\begin{tabular}{|llll|}
\hline \multicolumn{4}{c|}{ Table 3: Post- operative complications in both groups } \\
\hline Complications & Group I & Group II & P value \\
\hline Yes & 4 & 5 & 0.12 \\
No & 26 & 25 & \\
\hline
\end{tabular}

eters. Both antegrade and retrograde approaches are wellestablished techniques and both can be considered as therapeutic options. ${ }^{[6]}$ Improvements in endoscopic equipment, such as lithotripters and fiber optics, in conjunction with constantly improving surgical skills and experience have increased the efficiency and safety of minimal-invasive procedures for proximal ureteral stones management. ${ }^{[7]}$ Nowadays, antegrade and retrograde URSL are considered the primary treatment options for patients with large upper ureteral stones, supplanting the utilization of SWL. ${ }^{[8]}$ The present study compared antegrade percutaneous versus retrograde ureteroscopic lithotripsy in upper ureteric cases.

In this study, group I patients were treated with antegrade percutaneous and group II with retrograde ureterolithotripsy. Each group had 30 patients. Bhat et al, ${ }^{[9]}$ in their study APCUL and URSL were performed in 64 and 53 patients, respectively. The mean age and stone size were comparable between the two groups. The stone clearance rate at 1 month follow up was $93.75 \%$ in the antegrade group and $81.13 \%$ in the retrograde group $(\mathrm{P}=0.036)$. Mean anaesthesia time was significantly longer for the APCUL group while the actual mean operative 


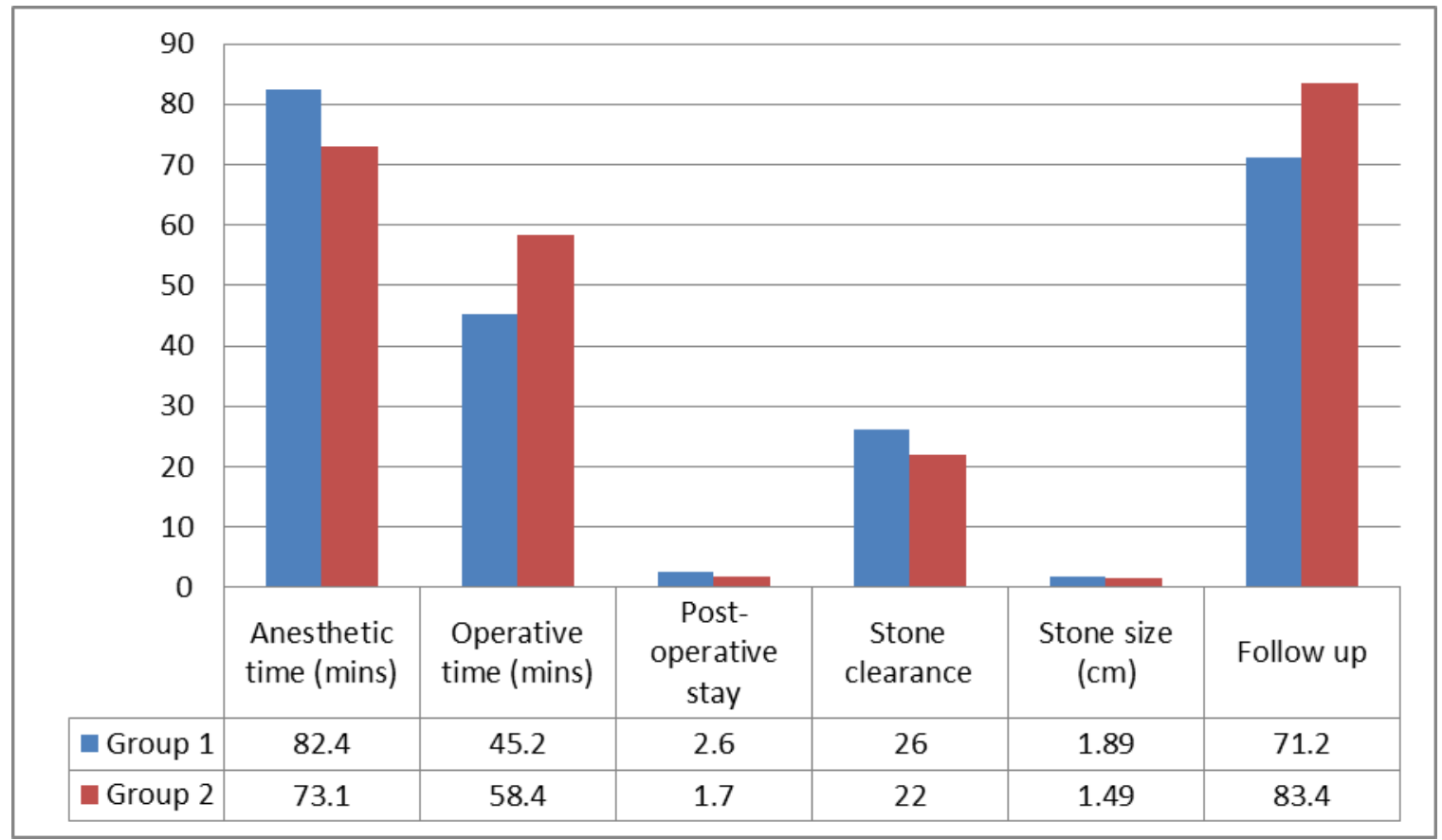

Figure 1: Comparison of parameters

time was significantly longer for the URSL group $(\mathrm{P}<0.001)$. The overall complication rate was higher in antegrade group $(\mathrm{P}$ $=0.804$ ), whereas most of the major complications (Clavien Grade III or more) occurred only in the URSL group ( $\mathrm{P}=$ 0.007). Blood transfusion was required only in the APCUL group $(7.8 \%$ versus $0 \% ; \mathrm{P}=0.50)$. In the URSL group, stone retropulsion occurred in four patients, of which three subsequently required shock wave lithotripsy and one required percutaneous nephrolithotomy in a second sitting.

We found that mean anesthetic time in group I was 82.4 minutes and in group II was 73.1 minutes, operative time was 45.2 minutes in group I and 58.4 minutes in group II, postoperative stay in group I was 2.6 days and in group II was 1.7 days, stone clearance was seen in 26 patients in group I and 22 in group II. Mean stone size in group I was $1.89 \mathrm{~cm}$ and in group II was $1.49 \mathrm{~cm}$. Follow ups days were 71.2 in group I and 83.4 in group II. Clavien-Dindo categorization grade 0 was seen in 16 in group I and 13 in group II, grade 1 in 10 in group I and 12 in group II and grade 2 in 4 in group I and 5 in group II. Sfoungaristos et al, ${ }^{[10]}$ included 57 patients. Thirty-four patients $(59.6 \%)$ underwent retrograde and 23 patients (40.4\%) underwent antegrade ureteroscopy. There was no significant difference in patients' demographics and stone characteristics between the groups. Stone-free rate was significantly higher $(p=0.033)$ in the antegrade group $(100 \%)$ compared to retrograde one (82.4\%). Fluoroscopy time, procedure duration, and length of hospitalization were significantly $(\mathrm{p}<0.001)$ lower in retrograde approach. On the other hand, the need for postoperative stenting was significantly lower in the antegrade group $(p<0.001)$. No difference was found between the groups $(p=0.745)$ regarding postoperative complications.

\section{Conclusion}

Authors found that antegrade percutaneous has better stone clearance rates as compared to retrograde ureterolithotripsy for an upper ureteric calculus.

\section{References}

1. Segura JW, Preminger GM, Assimos DG, Dretler SP, Kahn RI, Lingeman JE, et al. URETERAL STONES CLINICAL GUIDELINES PANEL SUMMARY REPORT ON THE MANAGEMENT OF URETERAL CALCULI. J Urol. 1997;158(5):1915-1921. Available from: https://dx. doi.org/10.1016/s0022-5347(01)64173-9. doi:10.1016/s00225347(01)64173-9.

2. Liong ML, Clayman RV, Gittes RF, Lingeman JE, Huffman JL, Lyon ES. Treatment Options for Proximal Ureteral Urolithiasis: Review and Recommendations. J Urol. 1989;141(3 Part 1):504-509. Available from: https://dx.doi.org/10.1016/s00225347(17)40874-3. doi:10.1016/s0022-5347(17)40874-3.

3. Ziaee SAM, Halimiasl P, Aminsharifi A, Shafi H, Beigi FMA, Basiri A. Management of 10-15-mm Proximal Ureteral Stones: Ureteroscopy or Extracorporeal Shockwave Lithotripsy? Urol. 
2008;71(1):28-31. Available from: https://dx.doi.org/10.1016/ j.urology.2007.08.025. doi:10.1016/j.urology.2007.08.025.

4. Park H, Park M, Park T. Two year experience with ureteral stones: Extracorporeal shockwave lithotripsy vs. ureteroscopic manipulation. J Endourol. 1998;12:501-505.

5. Kato Y, Yamaguchi S, Hori J, Okuyama M, Kakizaki H. Improvement of stone comminution by slow delivery rate of shock waves in extracorporeal lithotripsy. Int J Urol. 2006;13(12):1461-1465. Available from: https://dx.doi.org/10.1111/j.1442-2042.2006.01609.x. doi:10.1111/j.1442-2042.2006.01609.x.

6. Preminger GM, Tiselius HG, Assimos DG, Alken P, Buck C, Gallucci M, et al. 2007 Guideline for the Management of Ureteral Calculi. J Urol. 2007;178(6):2418-2434. Available from: https://dx.doi.org/10.1016/j.juro.2007.09.107. doi:10.1016/j.juro.2007.09.107.

7. Preminger GM. Management of Ureteral Calculi: The Debate Continues ... J Urol. 1992;148(3 Part 2):11021104. Available from: https://dx.doi.org/10.1016/s00225347(17)36831-3. doi:10.1016/s0022-5347(17)36831-3.

8. Sfoungaristos S, Mykoniatis I, Isid A, Gofrit ON, Rosenberg S, Hidas G. Retrograde versus Antegrade Approach for the Management of Large Proximal Ureteral Stones. Biomed Res Int. 2016;2016:6521461-6521461. Available from: https://dx.doi. org/10.1186/s40064-016-1677-8. doi:10.1155/2016/6521461.
9. Bhat A, Singh V, Bhat M, Khandelwal N, Bhat A. Comparison of antegrade percutaneous ureterolithotripsy and retrograde ureteroscopic lithotripsy for upper ureteric calculus with regard to stone clearance, morbidity, and complications. Indian J Urol. 2019;35:1-6.

10. Sfoungaristos S, Mykoniatis I, Isid A, Gofrit ON, Rosenberg S, Hidas G, et al. Retrograde versus Antegrade Approach for the Management of Large Proximal Ureteral Stones. BioMed Res Int. 2016;2016:1-4. Available from: https://dx.doi.org/10. 1155/2016/6521461. doi:10.1155/2016/6521461.

Copyright: (C) the author(s), 2020. It is an open-access article distributed under the terms of the Creative Commons Attribution License (CC BY 4.0), which permits authors to retain ownership of the copyright for their content, and allow anyone to download, reuse, reprint, modify, distribute and/or copy the content as long as the original authors and source are cited.

How to cite this article: Prasad AN, Prasad PVGS. Antegrade Percutaneous Versus Retrograde Ureteroscopic Lithotripsy in Upper Ureteric Cases. Acad. J Surg. 2020;3(1):84-87.

DOI: dx.doi.org/10.47008/ajs/2020.3.1.18

Source of Support: Nil, Conflict of Interest: None declared. 